\title{
Fracture of the Body's Hamate Bone: Open Reduction Internal Fixation by Double Approach-A Case Report
}

\section{Fractura del cuerpo del ganchoso: Reducción abierta y fijación interna mediante doble abordaje-A propósito de un caso.}

Jorge Salvador Marín ${ }^{1}$ Antonia Brotons Baile ${ }^{1} \quad$ Nuria Cardona Vives $^{1} \quad$ Jaime Francisco Vargas Prieto $^{1}$ José Manuel Pérez Alba ${ }^{1}$ José Fernando Martínez López ${ }^{1}$

1 Orthopedic Surgery and Trauma Service, Hospital Universitari de Sant Joan d'Alacant, Alicante, Spain

Rev Iberam Cir Mano 2018;46:126-130.
Address for correspondence Jorge Salvador Marín, MD, MSc, Hospital Universitari de Sant Joan d'Alacant Ctra. Nnal. 332, Alacant-Valencia, s/n, 03550 Sant Joan d'Alacant, Alicante, Spain (e-mail: salvadormarinj@gmail.com).

\section{Abstract \\ Keywords \\ - carpal fracture \\ - carpometacarpal dislocation \\ - double dorsal and palmar approach \\ - hamate fracture \\ - open reduction internal fixation \\ Resumen \\ Palabras Clave \\ - fractura del ganchoso \\ - fractura del carpo \\ - reducción abierta y fijación interna \\ - luxación carpometacarpiana \\ - doble abordaje dorsal y volar}

Hamate fractures are rare. Their treatment depends on the displacement and type of fracture. We present the case and surgical technique of a 33-year-old male patient, who is a manual worker, with a displaced fracture of the body of the hamate bone associated with dislocation of the fourth and fifth metacarpal (MC) bones. The patient was operated on with a double palmar and dorsal approach directly over the hamate and the body hook, respectively, which was performed to improve the control reduction and avoid damaging the neighboring vascular and nerve structures. The open reduction internal fixation (ORIF) was performed by inserting mini-screws in a dorsal to palmar direction. Later, the dislocations were reduced and fixed with Kirschner wires between the fourth and fifth MC bases, and between the fourth MC base and the capitate bone. The patient was discharged 2.5 months after the fracture. The Disabilities of the Arm, Shoulder and Hand (DASH) questionnaire outcome measure was 5 points at 6 months postsurgery.

Las fracturas del ganchoso son poco frecuentes y el tratamiento depende del desplazamiento y tipo de fractura. Se describe la actualidad del tema, y el caso y técnica quirúrgica de un varón de 33 años, trabajador manual que sufre una fractura desplazada del cuerpo del hueso ganchoso, con luxación asociada del $4^{\circ}$ y $5^{\circ}$ metacarpianos. El paciente fue intervenido realizando un doble abordaje volar y dorsal directo al gancho y cuerpo del ganchoso respectivamente para mejorar el control de la reducción y evitar el daño de las estructuras vasculo-nerviosas vecinas. Se osteosintetizó con tornillo desde dorsal a volar y redujeron y fijaron las luxaciones con agujas de Kirschner entre las bases del $4^{\circ}$ y $5^{\circ}$ MTC; y base de $4^{\circ}$ MTC y hueso grande. Fue dado de alta a los 2,5 meses de la fractura. El cuestionario DASH fue de 5 puntos a los 6 meses post fractura. received

July 24,2017

accepted

March 1, 2018

published online

June 5, 2018
DOI https://doi.org/

$10.1055 / \mathrm{s}-0038-1654722$.

ISSN 1698-8396.
Copyright $\odot 2018$ Thieme Revinter

Publicações Ltda, Rio de Janeiro, Brazil
License terms

c) $(1) \$$ 


\section{Introduction}

Hamate bone fractures are uncommon, representing only $\sim 2 \%$ of carpal fractures, according to some authors. ${ }^{1}$ They are usually classified according to the affected area: type I affects the hook, while in type II, the body of the hamate is the affected part. ${ }^{1}$ There is a subdivision of this classification proposed by Hirano et $\mathrm{al}^{2}$ to improve preoperative planning and description (-Fig. 1A). Cain et al (apub Sarabia et $\mathrm{al}^{3}$ ) proposed a specific classification when the fracture is related to carpometacarpal dislocation (-Fig. 1A). Hamate hook fractures occur mainly in sportsmen who use hand instruments by a mechanism of direct impact against the hook, while body fractures are often caused by trauma with the closed fist against an object. Stress fractures of this bone and avulsion fractures of the pisohamate ligament have also been described in the literature. ${ }^{4}$ The diagnosis is usually difficult and late due to delay in the medical visit and the physical examination, which is usually nonspecific. ${ }^{3}$ Anteroposterior (AP) and lateral radiographs (Rxs) should be taken as complementary tests. Computed tomography (CT) is necessary to establish a definitive diagnosis and perform the surgical planning. ${ }^{5}$ The decision between conservative or surgical treatment is based on the following criteria: stability, fracture displacement and joint involvement. ${ }^{1,3}$ The approach most frequently described in the literature is the dorsal approach, ${ }^{6}$ because of its lower complexity and also because it allows for an extensive body exposure.
The purpose of this article is to describe the double approach surgical technique for an uncommon displaced fracture of the body of the hamate bone associated with dislocation of the fourth and fifth metacarpals (MCs).

\section{Case Report}

A 33-year-old male patient, manual construction worker, went to the emergency room because he had fallen down the stairs at home. Upon physical examination, he had a dominant hand injury with pain and inflammation on the hypothenar eminence, which increased with palpation and ulnar deviation maneuvers as well as functional impotence of the fourth and fifth fingers of the hand. There was no visible deformity or neurovascular deficit. Anteroposterior (AP), lateral and oblique Rxs (-Fig. 2) showed a hamate bone fracture with dislocation of the fourth and fifth MCs. A CT scan was requested (-Fig. 3) to confirm the diagnosis, which showed a coronal longitudinal fracture with dorsal shattered fragment and displaced joint tract of the hamate bone, with dislocation of the fourth and fifth in the emergency room, a closed reduction was performed by manual traction and immobilized with an antebrachial splint plaster and a metal finger splint. The clinical case was presented at a clinical session, in which the surgical treatment of the fracture-dislocation through open reduction and internal fixation (ORIF) was chosen, using a double approach.
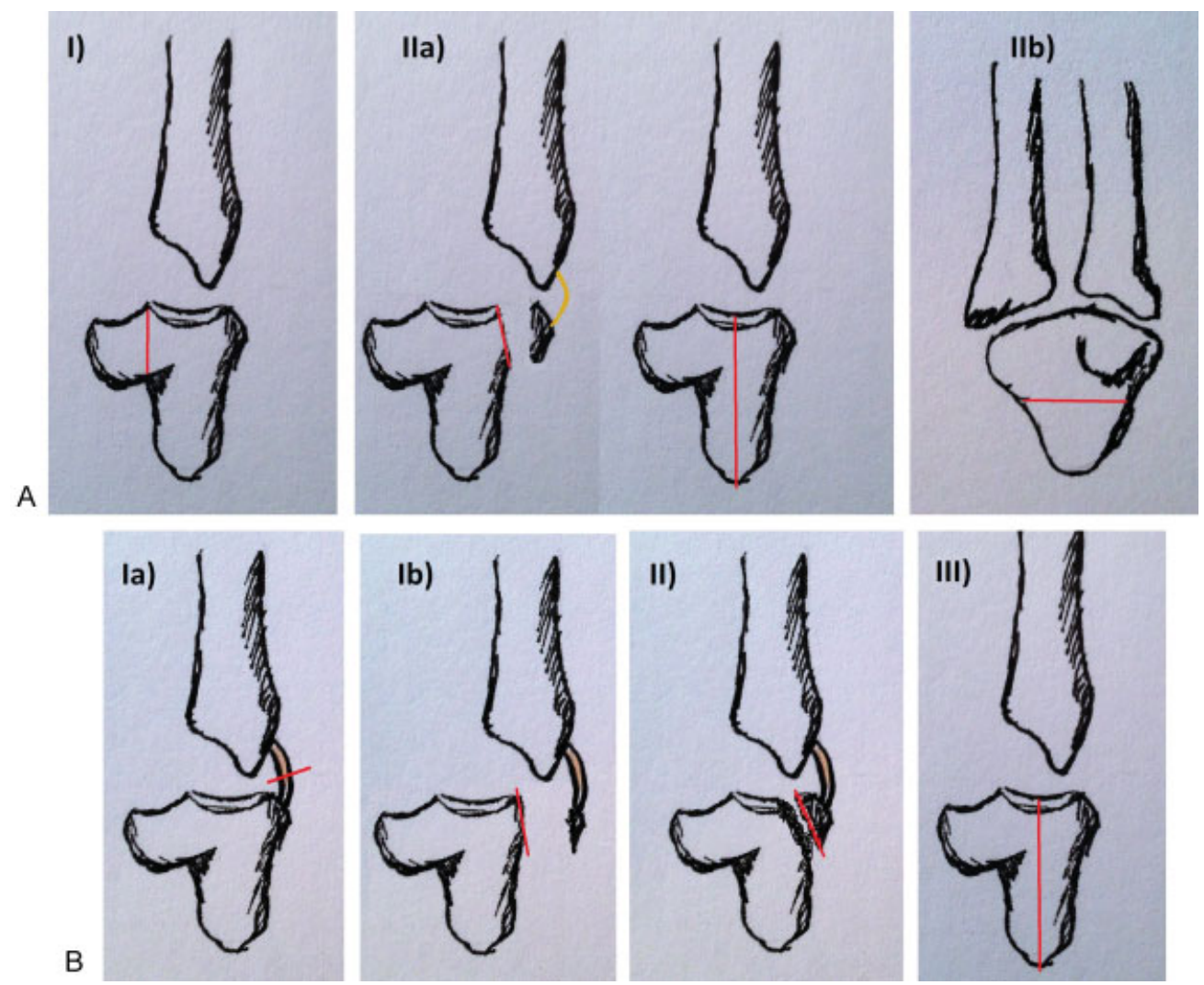

Fig. 1 A) Hirano et al. classification. ${ }^{2}$ B) Cain et al. classification associated with fourth and fifth metacarpal dislocation (apub Sarabia et al ${ }^{3}$ ). 

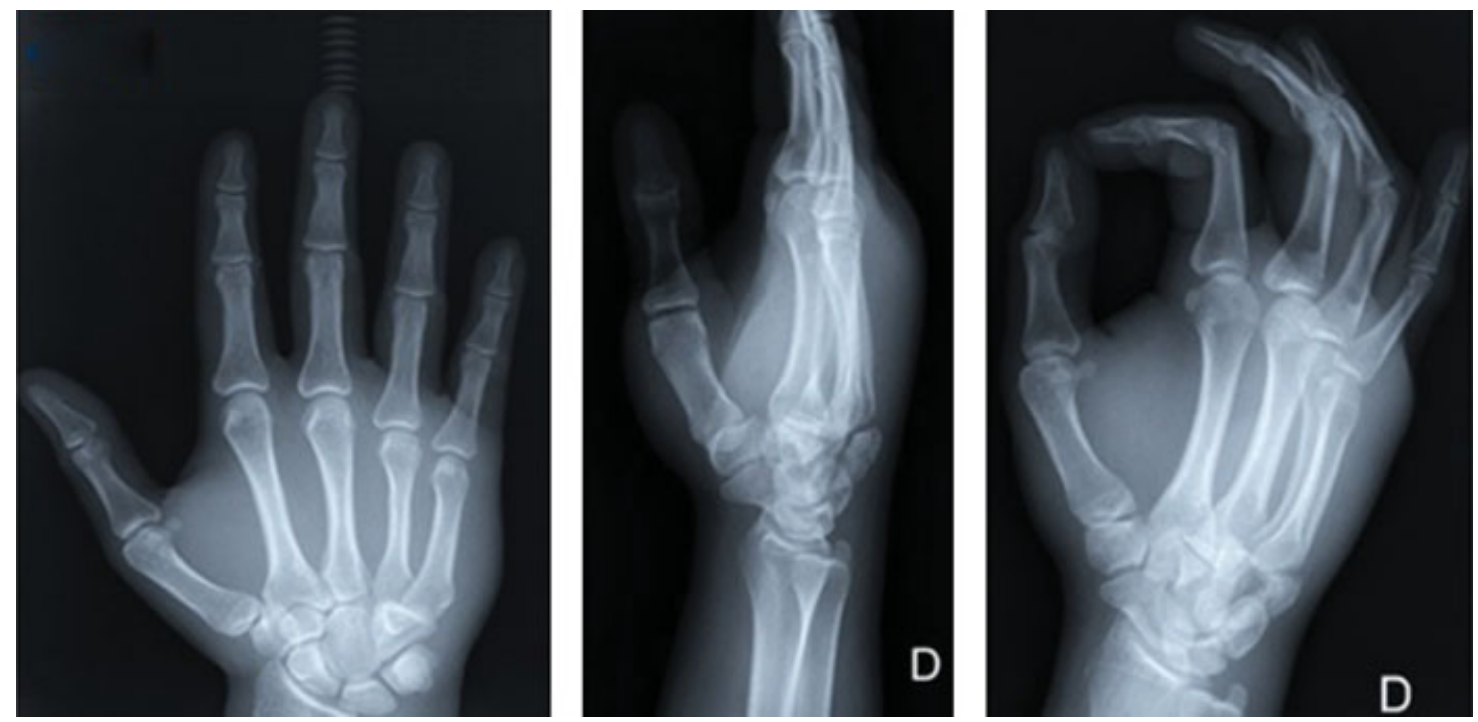

Fig. 2 Anteroposterior, lateral and oblique X-rays.

\section{Surgical Technique}

General anesthesia associated with ulnar nerve block was performed, antibiotic prophylaxis with cefazolin was administered and the ischemia cuff test was conducted. With the patient placed in supine position and accessory hand table, a double approach, volar and dorsal, was performed (- Fig. 4): Volar: direct to the hook. We refer to the ulnar artery and nerve. Dorsal: Direct to the body between the fourth and fifth extensor compartments. A reducing clamp was used on the body of the hamate from the dorsal approach and on the body from the volar approach as points of support. This way, we protected the artery and ulnar nerve that we have referenced, minimizing the possibility of injury. Next, a reduction was performed, and a provisional fixation of the fracture was made. Then, a Kirschner wire (KW) was threaded from volar to dorsal through the hamate hook (controlling and separating the vascular-nervous package), the brocade and the final fixation with a cannulated screw type Acutrack mini
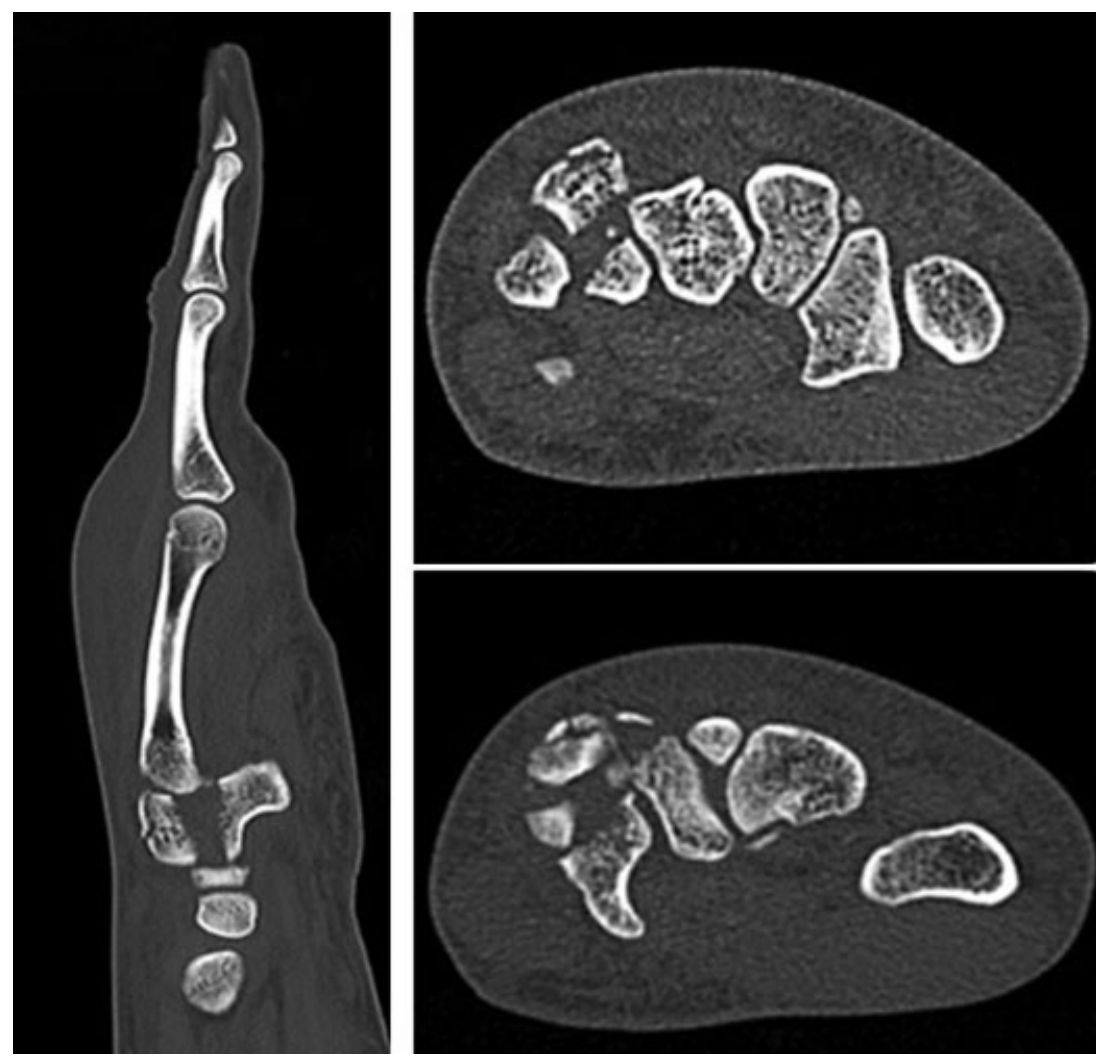

Fig. 3 Hand computed tomography scan with hamate fracture. Sagittal and axial views are shown. 

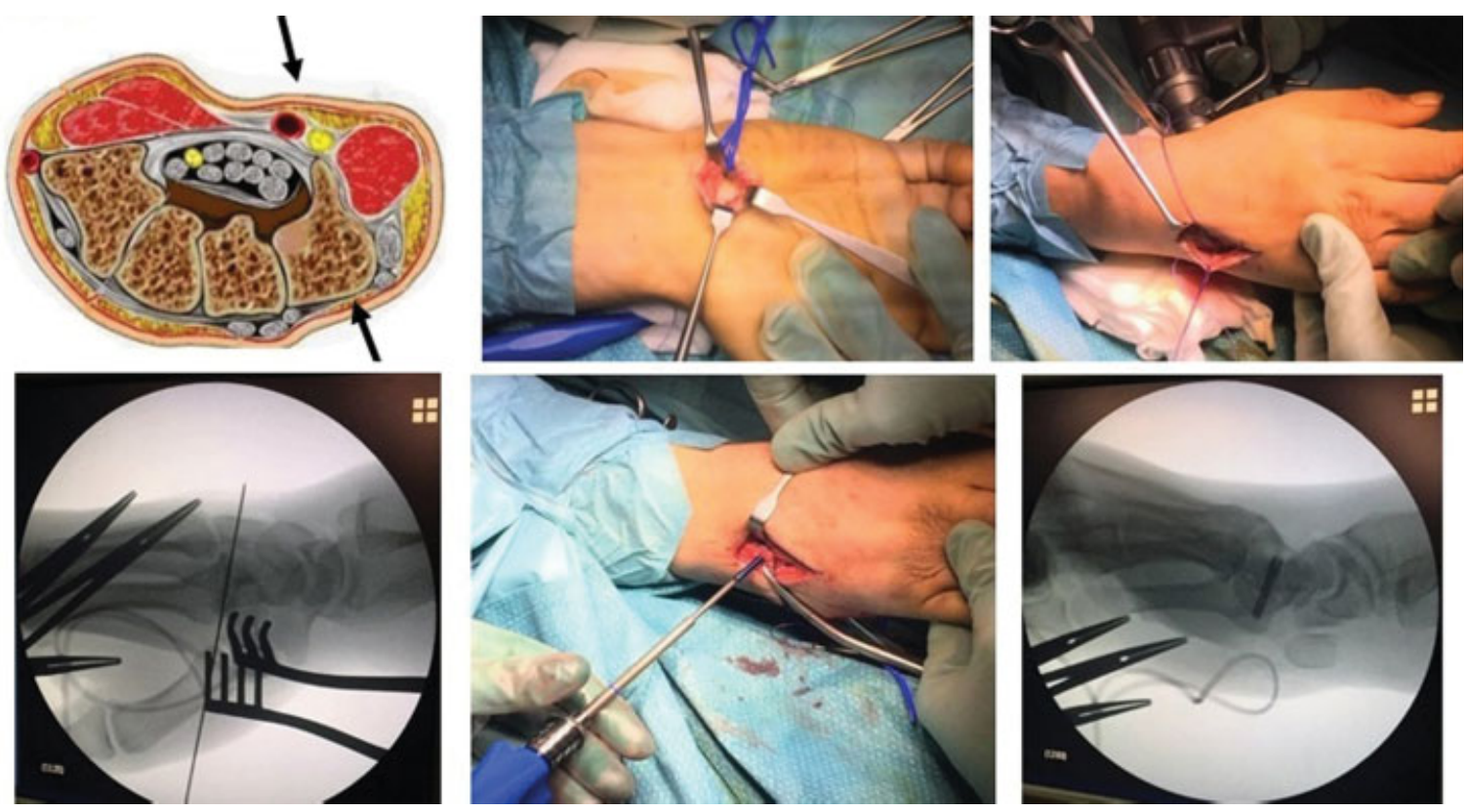

Fig. 4 Double approach, volar and dorsal. Open reduction internal fixation.

(Acumed, Hillsboro, OR, USA) of $3.5 \mathrm{~mm} \times 20 \mathrm{~mm}$ from dorsal to palmar through the body of the hamate. Finally, the reduction and fixation of the dislocations of the MCs were made with a KW pierced from the fifth to the fourth MCs, and from the fourth MC to the capitate bone. It was immobilized with an antebrachial posterior splint plaster in the intrinsic plus position (-Fig. 5). The duration of the surgery was of 1 hour and 13 minutes from the opening to the closing of the skin. Fluoroscopy control was necessary.

\section{Postoperative, Rehabilitation and Follow-up in External Query}

The Kirschner wire removal and hand immobilization were performed 6 weeks after the surgery. This was the stage at which the rehabilitation began. The patient was discharged in 10 weeks. He returned to work with complete mobility and absence of pain. The Disabilities of the Arm, Shoulder and
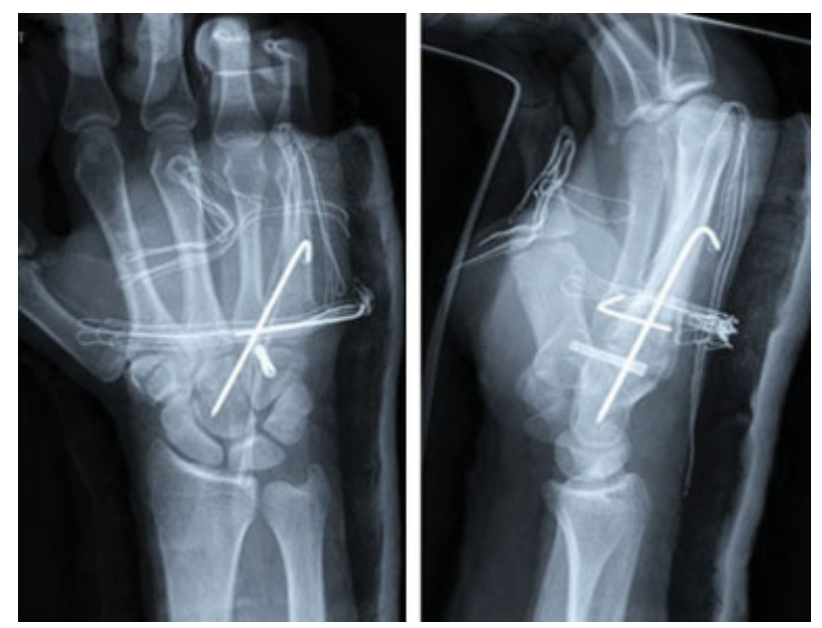

Fig.5 Post-surgery X-rays. Definitive fixation.
Hand (DASH) questionnaire outcome measure was 5 points at 6 months post-fracture with complete non-painful mobility. The CT scan at 6 months postsurgery showed signs of consolidation, without 96 collapse or secondary displacement of the fracture (-Fig. $\mathbf{6}$ ).

\section{Discussion}

An extremely rare fracture is discussed in the present study. It is a longitudinal coronal body fracture, with dorsal fragment and dislocation of the fourth and fifth MCs. Some articles describe this association. ${ }^{7}$ Cain et al (apub Sarabia et $\mathrm{al}^{3}$ ), divide the fractures into type IA: subluxation of the base of the fifth MC and rupture of the dorsal carpometacarpal ligament with no hamate injury; type IB: dorsal hook fracture; type II: dorsal comminuted hook fracture; and type III: longitudinal coronal hook fracture. The fracture presented in this case is type III, with fragmented dorsal comminute. The mechanisms of production are described in the literature. ${ }^{3}$ In the case discussed in the present study, there was probably a combination of two mechanisms: the axial load through the fourth and fifth MCs caused a type III injury, and the dorsal destruction was caused by the avulsion of the dorsal carpometacarpal ligament.

On examination, that kinds of fractures usually present persistent pain at the level of the hypothenar eminence, and there may be paresthesia and weakness in the ulnar nerve area if the fracture is displaced and is compromising the nerve during its passage through the Guyon canal. ${ }^{1}$ Anteroposterior, lateral and oblique Rxs were obtained for the diagnosis, and a CT was requested for the definitive diagnosis, which was also used for surgical planning. Magnetic resonance imaging (MRI) is reserved for the diagnosis of injuries to adjacent structures. The most frequent approach described in the literature is the dorsal through the fourth 

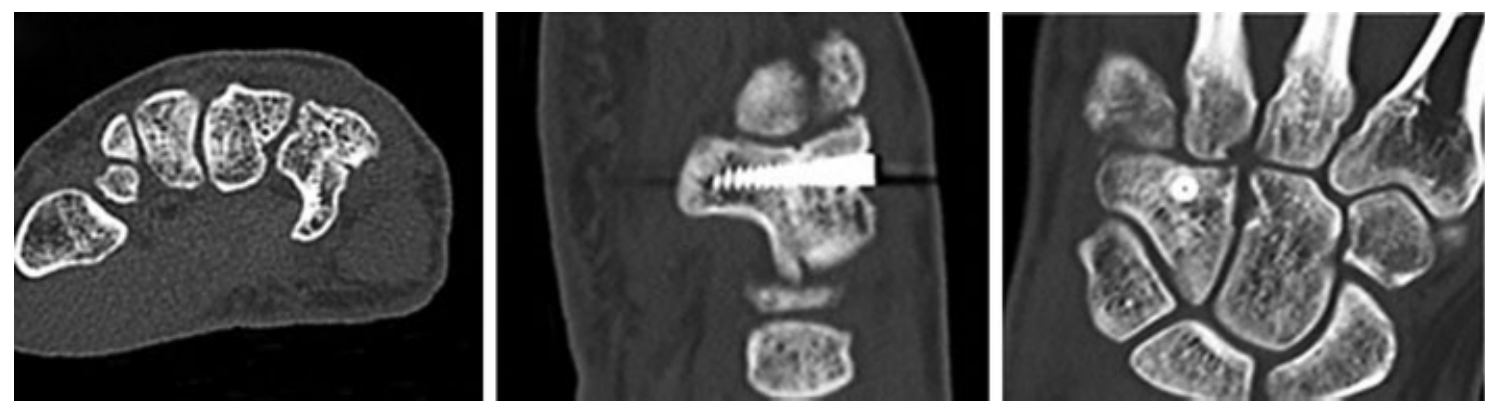

Fig. 6 Computed tomography 6 months postsurgery. Coronal, axial and sagittal views are shown.

and fifth extensor compartment ${ }^{6}$ because it is less complex, fast, with good exposure of the hamate body and minimal involvement of the neighboring structures that remain in the volar face. However, the anatomical relationships of the hamate bone may facilitate the appearance of complications, such as ulnar nerve sectioning, during the approach, ${ }^{8}$ median and ulnar nerve injuries, due to compression by a displaced fragment, ${ }^{1,3}$ or ulnar artery occlusions, subsequently diagnosed with ultrasound. ${ }^{9}$ Other complications associated with the displacement of the fracture are tenosynovitis, and rupture of the fourth and fifth finger flexors caused by erosion against the bone surface of the hamate hook, because it is a trochlea for these tendons. For all of these reasons, and taking into account the particularities of the fracture discussed in the present study, we decided to apply a double approach; first, controlling the dorsal comminute fragment, and then, controlling the ulnar artery and nerve by the volar side during reduction and fixation.

In addition, the anatomical reduction was facilitated by approaching the fracture from two sides and using a reducer clamp to apply interfragmentary compression. The choice of treatment is based on the stability and displacement of the fracture, ${ }^{1,3}$ although it is also conditioned by the fracture line and associated injuries. The conservative treatment of nondisplaced hamate hook fractures has a consolidation rate close to $50 \%$, which implies a high failure rate, with an increased number of palmar fractures because of the poor vascularization of the distal area of the hook. ${ }^{10}$ Surgical treatment is recommended when the fracture is displaced, or when there is compression of the ulnar nerve. Multiple possibilities have been described: fracture fragment pull out, osteosynthesis with Herbert screws, KWs, mini-screw or preformed low-profile plates. ${ }^{5,6}$ Some authors recommend the excision of the fragment as an elective treatment. ${ }^{1}$ The hamate hook acts as an insertion of the transverse carpal ligament, the pisohamate ligament and the flexor and opponens digiti minimi muscles, although several studies have not been able to show any decrease in mobility or force afterwards. ${ }^{1}$ Others propose the fixation with a dorsal percutaneous screw in the case of nonunion after the conservative treatment. It is a difficult surgical technique, and the functional results are similar to the excision of the fragment, but the healing time is shorter. Non-displaced body fractures are relatively stable and can be treated by immobilization for a period of 4 to 6 weeks. For displaced body fractures, ORIF using preformed low-profile plates or compression screws is recommended. ${ }^{5,6}$ Fixation with KWs may be necessary if there is an associated carpometacarpal luxation. This procedure usually fixes the fourth and fifth MCs to the third MC and the capitate bone in unstable type III fracture-dislocations, according to the fracture classification proposed by Cain et al (apub Sarabia et $\mathrm{al}^{3}$ ); leaving conservative treatment through immobilization for type IA and IB fractures. ${ }^{3}$

The most frequent complications are symptomatic pseudarthrosis, avascular necrosis and posttraumatic carpometacarpal arthritis. In the case discussed in the present study, the surgical treatment used obtained good functional results. We believe that the volar and dorsal approach is a possible option for the treatment of these types of fractures to improve the reduction control and avoid damage to the vascular-nerve structures.

\section{References}

1 Suh N, Ek ET, Wolfe SW. Carpal fractures. J Hand Surg Am 2014;39 (04):785-791, quiz 791

2 Hirano K, Inoue G. Classification and treatment of hamate fractures. Hand Surg 2005;10(2-3):151-157

3 Sarabia Condés JM, Ibañez Martínez L, Sánchez Carrasco MA, Carrillo Julia FJ, Salmerón Martínez EL. Hamate fractures. Rev Esp Cir Ortop Traumatol 2015t;59(05):299-306

4 Guha AR, Marynissen H. Stress fracture of the hook of the hamate. Br J Sports Med 2002;36(03):224-225

5 Kaneko K, Ono A, Uta S, et al. Hamatometacarpal fracture-dislocation: distinctive three dimensional computed tomographic appearance. Chir Main 2002;21(01):41-45

6 Scheufler O, Radmer S, Bogusch G, Andresen R. Minimal Invasive Fixation of Hamate Hook Fractures Through a Dorsal Percutaneous Approach Using a Mini Compression Screw: An Experimental Feasibility Study. Eur J Trauma Emerg Surg 2009;35(04): 397-402

7 Brinkman JN, Hartholt KA, de Vries MR. Multiple carpometacarpal dislocations and an associated fracture of the hamate: an uncommon injury. BMJ Case Rep 2016;2016:2016

8 Fredericson M, Kim BJ, Date ES, McAdams TR. Injury to the deep motor branch of the ulnar nerve during hook of hamate excision. Orthopedics 2006;29(05):456-458

9 Maier RM, Hughes M, Katranji A. Patient with a Hook of the Hamate Fracture Presenting as Vascular Occlusion: Diagnosis Made with Bedside Ultrasound. J Emerg Med 2016;51(01):63-65

10 Failla JM. Hook of hamate vascularity: vulnerability to osteonecrosis and nonunion. J Hand Surg Am 1993;18(06):1075-1079 